\section{Primary pleural epithelioid hemangioendothelioma}

\author{
Sarra Ben Rejeb, ${ }^{1}$ \\ Dorra Ben Ghachem, ${ }^{1}$ Amen Dhaoui, ${ }^{1}$ \\ Salma Ben Marzouk, ${ }^{2}$ Khadija Bellil ${ }^{1}$ \\ ${ }^{1}$ Pathology Department; ${ }^{2}$ Radiology \\ Department, Security Forces Hospital of \\ Tunis, Marsa, Tunisia
}

\begin{abstract}
Epithelioid hemangioendothelioma (EHE) is a rare vascular tumor exceptionally involving the pleura with less than 30 cases reported in literature. We herein describe another case of pleural EHE in a 79-year-old man with medical history of chronic obstructive pulmonary disease and high blood pressure. He presented rightsided pleural effusion. Computerized tomography revealed multifocal pleural thickening and effusion. Pleural biopsy was performed. Microscopically, the tumor showed a biphasic pattern with cords and nests of epithelioid cells showing mild atypia and rare mitosis with intracytoplasmic lumina containing red blood cells. The second pattern is composed of spindle-shaped cells with occasional necrosis. The tumor cells were positive for CD34 and focally with CK7. The diagnosis of EHE was made.
\end{abstract}

\section{Introduction}

Epithelioid hemangioendothelioma (EHE) is a rare vascular tumor that might develop in any tissue but which has predilection for the liver, heart, lung and bone. Pulmonary epithelioid hemangioendothelioma $(\mathrm{PEH})$ was first described in 1975 by Dail and Leibow, it was considered as an aggressive bronchoalveolar cell carcinoma. ${ }^{1}$ Primary pleural location is extremely rare with less than 30 cases reported in the literature as analyzed in Table $1 .^{2-19}$ The aim of this report is to present the case of a 79-year-old man who was diagnosed with pleural EHE and summarize the limited published data concerning this rare neoplasm in order to improve the diagnosis and its management.

\section{Case Report}

A 79-year-old man with a family history of colorectal cancer and past medical history of chronic obstructive pulmonary disease (COPD) and high blood pressure presented with right-sided chest pain and breathlessness associated to a recent weight loss. On physical examination there was dullness to percussion and decreased breath sounds over the right hemithorax with signs of right heart failure. Chest radiography confirmed the presence of a moderate right pleural effusion. A Computerized tomography (CT) of the thorax, abdomen and pelvis was performed and revealed a mild right pleural effusion with multifocal pleural thickening. No pulmonary nodules were seen. Three enlarged iliac lymph node were observed. Based on the family history of colorectal cancer, pleural and lymph node metastasis from a primary gastrointestinal cancer were highly suspected. However, no abnormalities were noted on fibro-colonoscopy. Image-guided pleural biopsy was performed. Microscopically, the tumor showed a biphasic pattern with cords and nests of epithelioid cells set in a myxoid stroma. Some cells show mild atypia and rare mitosis with intracytoplasmic lumina containing red blood cells. The second pattern is composed of spindle-shaped cells with occasional area of necrosis (Figures 1 and 2).

Immunohistochemically, the tumor cells were positive for CD34 and focally with CK7 (Figures 3 and 4). The diagnosis of EHE with high-grade pattern was made. Although, no codified therapies for this cancer have been established yet, the patient was not candidate for surgery considering the extent and bilaterality of the nodules and his hard medical history. Several cycles of chemotherapy with Etoposide and Cisplatin were decided as the lesions were diffuse and bilateral with suspicion of lymph node involvement.

Unfortunately, during his stay in the hospital, the patient developed acute decompensation of his COPD which required mechanical ventilation and intensive care. He sadly died one month later because of cardiac and respiratory failure.

\section{Discussion}

The accumulation of fluid in the pleural space is a common and non-specific manifestation of a wide range of diseases which could be pulmonary, pleural or extrapulmonary. Lung cancer (40\%) and breast cancer $(25 \%)$ are the most common metastatic tumors to the pleura. About $10 \%$ of all malignant pleural effusions are due to primary cancers arising from the pleura mainly represented by malignant mesothelioma $(>90 \%)$ followed by other rare neoplasm. ${ }^{2}$

EHE is an extremely rare tumor affecting the pleura with less than thirty cases described in literature. ${ }^{3}$ Analysis of these cases revealed a variable epidemiologic profile. Patients diagnosed with EHE of the pleura are mostly men with a gender ratio of
Correspondence: Sarra Ben Rejeb, Pathology Department, Security Forces Hospital of Tunis, Manarat Al Bouhaira Rce Rial StreetLac2-1053, Marsa, Tunisia.

Tel.: 0021623344510.

E-mail: sarrabenrejeb88@yahoo.fr

Key words: Epithelioid hemangioendothelioma; Pleura; Vascular tumor; Effusion.

Contributions: SBR participated in elaborating diagnosis and wrote the manuscript; DBG contributed to the conception of the manuscript and pathological analysis; $\mathrm{AD}$ participated in revising it critically for important intellectual content; SBM contributed to radiologic diagnosis and provided patient data; KB confirmed diagnosis, revised and approved the manuscript.

Conflict of interest: the authors declare no potential conflict of interest.

Funding: none.

Received for publication: 10 October 2016.

Revision received: 4 December 2017.

Accepted for publication: 24 June 2018.

This work is licensed under a Creative Commons Attribution NonCommercial 4.0 License (CC BY-NC 4.0).

(C) Copyright S.B. Rejeb et al., 2018

Licensee PAGEPress, Italy

Chest Disease Reports 2018; 6:6336

doi:10.4081/cdr.2018.6336

2,75 . The mean age at onset of symptoms is 46,84 . No particular family or past medical history is associated to EHE, one case have been reported in a patient with a history of exposure to asbestos. ${ }^{11}$ The main complaints of patients in this analysis are non specific symptoms such as dyspnea, cough, chest pain and weight loss. ${ }^{3-20}$ Only two cases have been discovered incidentally on routine chest radiography, ${ }^{5,9}$ Imaging shows in all cases either effusion or thickening of the pleura associated in some cases to lung nodules. ${ }^{3-20}$ As EHE is a very rare cause of pleural disease, more common etiology need to be ruled out firstly. In our case, the pleural effusion was thought to be resulting from metastasis of digestive cancer and so the patient underwent useless investigations leading to a delay in the proper diagnosis. Thus, considering the aggressive nature of this tumor, a quick and collaborative move of the medical team should be made in order to establish an early diagnosis. Pleural biopsy with pathological examination is the key for diagnosis. Microscopically, the tumor is intermediate between angiosarcoma and hemangioma. ${ }^{1}$ It is characterized by nests and cords of spindle to epithelioid cells 
embedded in a hyaline, myxoid, chondroid or collagenous stroma. ${ }^{21}$ The cells show prominent cytoplasmic vacuoles containing red blood cells (reminiscent of primitive vascular channels). In some cases there are solid nests of tumor cells displaying cytological atypia together with increased mitotic activity (more than 1 per $10 \mathrm{HPF}$ ) and areas of necrosis. On immunohistochemical analysis, the tumor cells express endothelial markers: CD31, CD34 and factor VIII. In some cases, they are positive for smooth muscle actin and cytokeratin. ${ }^{22}$ Epithelial membrane antigen (EMA) is negative unlike other epithelial tumours. EHE of the pleura may be confused with mesothelioma, however positive staining for vascular markers on immunohistochemistry is help- ful to distinguish EHE from mesothelioma. Depending on the degree of atypia and the presence of necrosis, EHE can mimic angiosarcoma especially when the tumor is highly aggressive. Immunohistochemistry do not contribute much to distinguish between EHE and epithelioid angiosarcoma. However, it is not well defined whether EHE is a distinctive entity or an intermedi-

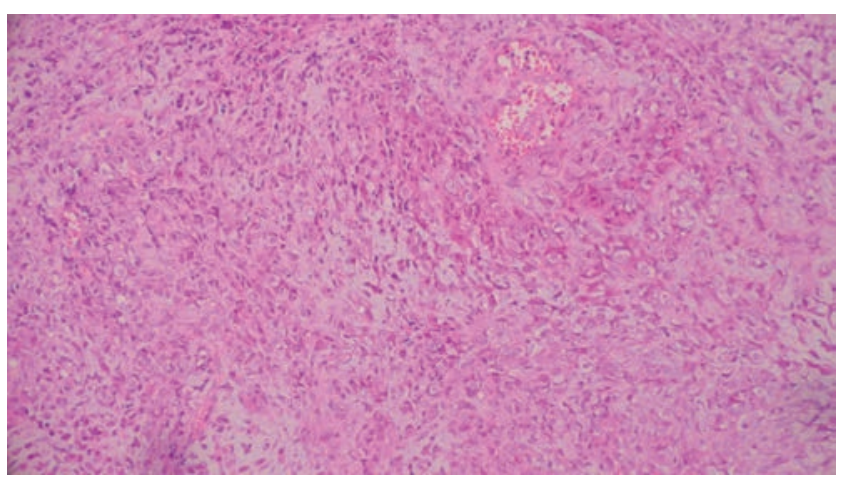

Figure 1. HE X 200: Tumor proliferation showing a biphasic pattern with cords and nests of epithelioid cells set in a myxoid stroma intermingled with spindle shaped cells.

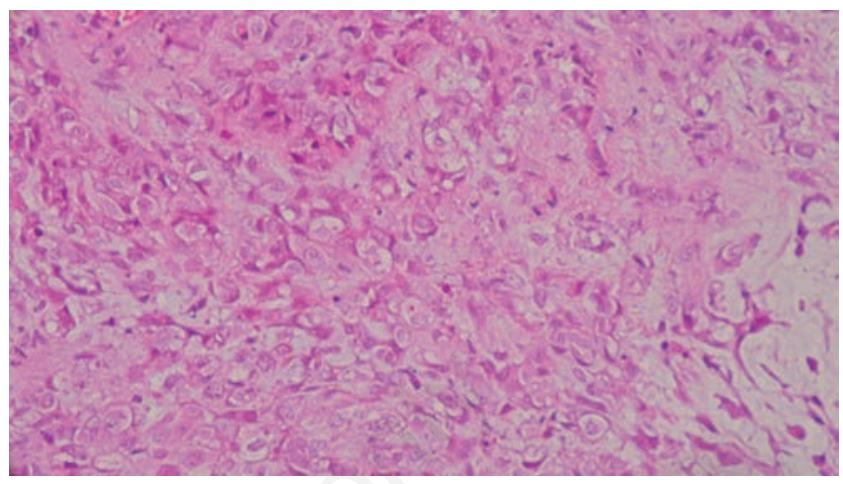

Figure 2. HE X 400: The epithelioid cells with intracytoplasmic lumina containing red blood cells.

Table 1. Primary pleural location: 30 cases reported in the literature. Modified from tables in previous reports by Lee $e t$ al., ${ }^{7}$ MarquezMedina et al., ${ }^{10}$ and Salijevska et al. $^{3}$

\begin{tabular}{|c|c|c|c|c|c|}
\hline Authors & $\begin{array}{l}\text { Agel } \\
\text { Gender }\end{array}$ & $\begin{array}{l}\text { Clinical } \\
\text { presentation }\end{array}$ & $\begin{array}{l}\text { Radiological } \\
\text { findings }\end{array}$ & Treatment & $\begin{array}{l}\text { Survival } \\
\text { (months) }\end{array}$ \\
\hline Pinet, $1999^{5}$ & $50 / \mathrm{F}$ & Incidentally on chest Radiography & Pleural effusion & Carboplatin, etoposide & $>18$ \\
\hline Crotty et al., $2000^{6}$ & $\begin{array}{l}51-71 / M \\
(\mathrm{n}=4)\end{array}$ & $\begin{array}{l}\text { Chest pain, dyspnea, cough, } \\
\text { fever, weight loss }\end{array}$ & & & \\
\hline Lee et al., $2008^{4}$ & $31 / F$ & Chest pain & Pleural thickening & Adriamycin, MAID & 10 \\
\hline Lazarus, $2011^{7}$ & $42 / M(n=2)$ & Cough, dyspnea, chest pain, fever & Pleural effusion & $\begin{array}{l}\text { *Taxol+bevacizumab } \\
\text { *Carboplatin, etoposide and bevacizumab }\end{array}$ & $\begin{array}{l}* 8 \\
* 6\end{array}$ \\
\hline $\begin{array}{l}\text { Yousem and } \\
\text { Hochholzer, } 1987^{8}\end{array}$ & $4 / \mathrm{M}$ & Dyspnea & Pleural effusion & None & 3 \\
\hline Lin, $1996^{9}$ & $36-58 / \mathrm{M}(\mathrm{n}=6)$ & Incidentally & Pleural effusion & & \\
\hline $\begin{array}{l}\text { Al Sharim } \\
\text { et al., } 2005^{10}\end{array}$ & $51 / \mathrm{M}$ & Cough, dyspnea & Pleural effusion & INF-alpha & $>24$ \\
\hline Vittorio, 2004 ${ }^{11}$ & $61 / \mathrm{M}$ & Chest pain & $\begin{array}{l}\text { Pleural effusion } \\
\text { and thickening }\end{array}$ & Cisplatin, etoposide & 3 \\
\hline Saqi, $2007^{12}$ & $37 / \mathrm{M}$ & Dyspnea, chest pain & Pleural effusion & Not specified & Not specified \\
\hline Liu et al., $2010^{13}$ & $80 / \mathrm{M}$ & Dyspnea & Pleural effusion & Surgery + chemotherapy (not specified) & 6 \\
\hline Bocchino, $2010^{14}$ & $58 / \mathrm{F}$ & Cough,dyspnea, chest pain & Pleural nodule & None & 3 \\
\hline Andre, $2010^{15}$ & $65 / \mathrm{F}$ & Chest pain & Pleural effusion & Carboplatin, etoposide & 6 \\
\hline Kim et al., $2011^{16}$ & $46 / \mathrm{F}$ & Cough, chest disconfort & Pleural effusion & Surgery, Carboplatin, Etoposide & $>22$ \\
\hline $\begin{array}{l}\text { Marquez- } \\
\text { Medina, } 2011^{17}\end{array}$ & $85 / \mathrm{M}$ & Chest, fatigue, weight loss & Pleural effusion & None & 7 \\
\hline Bansal, $2012^{18}$ & $51 / F$ & Chest pain, weight loss & $\begin{array}{l}\text { Pleural effusion } \\
\text { and thickening }\end{array}$ & Doxorubicin & 4 \\
\hline $\mathrm{Yu}, 2013^{19}$ & $39 / \mathrm{F}$ & Dyspnea & Pleural mass & Surgery, Carboplatin, etoposide & $>14$ \\
\hline Ha, $2014^{20}$ & $71 / \mathrm{M}$ & Cough, dyspnea, fatigue & Pleural effusion & Not specified & Not specified \\
\hline Salijevska $2015^{3}$ & $36 / F$ & Chest pain & Whiteout & Paclitaxel & 6 \\
\hline This case & $79 / \mathrm{M}$ & Chest pain, dyspnea & $\begin{array}{l}\text { Pleural effusion } \\
\text { and thickening + LN + }\end{array}$ & None & 1 \\
\hline
\end{tabular}

M, male; F, female; $\mathrm{LN}+$ : Lymph node metastasis. 


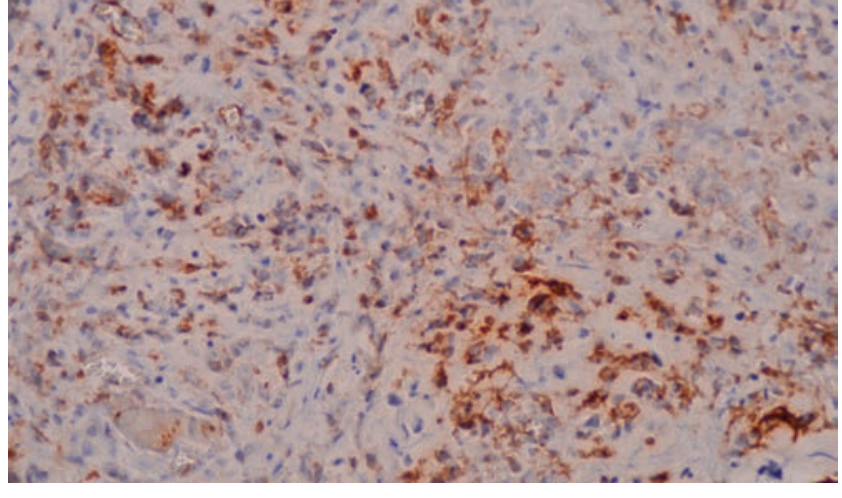

Figure 3. IHC X 200: The epithelioid cells stains strongly with

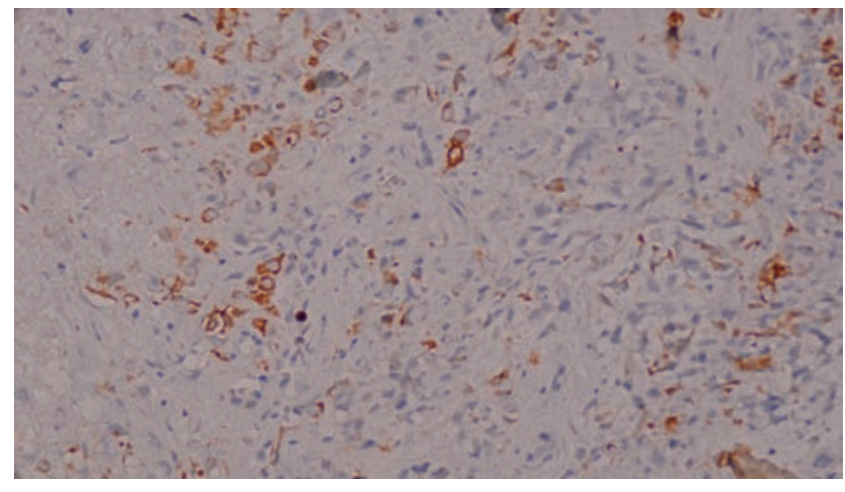

Figure 4. IHC X 200: The tumor cells show focal staining for CK7. ate state of endothelial dedifferenciation with a variable and unpredictable prognosis. ${ }^{1}$ Although, there is not a well established management algorithm, surgery and chemotherapy are better alternatives. Of patients who received chemotherapy, combination of Carboplatin and Etoposide have shown better results with an improved overall survival time. ${ }^{5,16,19}$ In our case, the patient did not receive any chemotherapy because of a poor general state. Up to now, the few reported cases of pleural EHE have revealed poor prognosis with a surviving period varying from 3 to more than 24 months. In our case, the tumor was highly aggressive and the patient died 1 within a month because of additional complications and delay in diagnosis.

\section{Conclusions}

It is worth bearing in mind that pleural EHE may reveal itself as pleural effusion. Considering the rarity and the aggressive behavior of this neoplasm, it is important we continue to collect data through case reporting in order to establish clinical and prognostic profile of this tumor and standardize its management.

\section{References}

1. Dail DH, Averill AL, Gmelich JT, et al. Intravascular, bronchiolar, and alveolar tumor of the lung (IVBAT). An analysis of twenty cases of a peculiar sclerosing endothelial tumor. Cancer 1983;51:45264.

2. Zarogoulidis K, Zarogoulidis P, Darwiche $\mathrm{K}$, et al. Malignant pleural effusion and algorithm management. J Thorac Dis 2013;5:413-9.

3. Salijevska J, Watson R, Clifford A, et al. Pleural epithelioid hemangioendothe- lioma: literature summary and novel case report. J Clin Med Res 2015;7: 566-70.

4. Lee YJ, Chung MJ, Jeong $\mathrm{KC}$, et al. Pleural epithelioid hemangioendothelioma. Yonsei Med J 2008;49:1036-40.

5. Pinet C, Magnan A, Garbe L, et al. Aggressive form of pleural epithelioid haemangioendothelioma: complete response after chemotherapy. Eur Respir J 1999;14:237-8.

6. Crotty EJ, McAdams HP, Erasmus JJ, et al. Epithelioid hemangioendothelioma of the pleura: clinical and radiologic features. AJR Am J Roentgenol 2000; 175:1545-9.

7. Lazarus A, Fuhrer G, Malekiani C, et al. Primary pleural epithelioid hemangioendothelioma (EHE)-two cases and review of the literature. Clin Respir $\mathrm{J}$ 2011;5:1-5.

8. Yousem SA, Hochholzer L. Unusual thoracic manifestations of epithelioid hemangioendothelioma. Arch Pathol Lab Med 1987;111:459-63.

9. Lin BT, Colby T, Gown AM, et al. Malignant vascular tumors of the serous membranes mimicking mesothelioma. A report of 14 cases. Am J Surg Pathol 1996;20:1431-9.

10. Al-Shraim M, Mahboub B, Neligan PC, et al. Primary pleural epithelioid haemangioendothelioma with metastases to the skin. A case report and literature review. J Clin Pathol 2005;58:107-9.

11. Vitorio P, Coletta E, Morrone N, et al. Epithelioid hemangioendothelioma of the pleura. J Bras Pneumol 2004;30:1-5.

12. Saqi A, Nisbet L, Gagneja P, et al. Primary pleural epithelioid hemangioendothelioma with rhabdoid phenotype: report and review of the literature. Diagn Cytopathol 2007;35:203-8.

13. Liu JX, Shiau MC, Nonaka D. An 80year-old man with shortness of breath and large right-sided pleural effusion. Chest 2010;138:1247-52.

14. Bocchino M, Barra E, Lassandro F, et al. Primary pleural haemangioendothelioma in an Italian female patient: a case report and review of the literature. Monaldi Arch Chest Dis 2010;73:1359.

15. Andre ST, Valente C, Paiva B, et al. Epithelioid hemangioendothelioma of the pleura - A rare presentation of a clinical case. Rev Port Pneumol 2010;16: 477-82.

16. Kim EA, Lele SM, Lackner RP. Primary pleural epithelioid hemangioendothelioma. Ann Thorac Surg 2011;91:301-2.

17. Marquez-Medina D, SamamePerezvargas JC, Tuset-DerAbrain N, et al. Pleural epithelioid hemangioendothelioma in an elderly patient. A case report and review of the literature. Lung Cancer 2011;73:116-9.

18. Bansal A, Chawla M, Cohen PJ, Kwon JS. Pleural epithelioid hemangioendothelioma. Lung 2012;190:469-70.

19. Yu L, Gu T, Xiu Z, et al. Primary pleural epithelioid hemangioendothelioma compressing the myocardium. J Card Surg 2013;28:266-8.

20. Ha SY, Choi IH, Han J, et al. Pleural epithelioid hemangioendothelioma harboring CAMTA1 rearrangement. Lung Cancer 2014;83:411-5.

21. Weiss S, Enzinger F. Epithelioid hemangioendothelioma. Cancer 1982;50: 970-81.

22. Miettinen M, Lindemayer AE, Chaubal A. Endothelial cells markers CD31, $\mathrm{C} 34$ and BNH9 antibody to $\mathrm{H}$ and Yantigens. Evaluation of their specificity and sensitivity in the diagnosis of vascular tumors and comparison with Von Willebrand factor. Mod Pathol 1994;14:141-9. 